\title{
Materials based on modified gypsum for facade systems
}

\author{
A.D. Zhukov"1, 2, 3 (D) I.V. Bessonov² (D), E.Yu. Bobrova3* (iD, E.A. Gorbunova1, 2 (D), B.A. Demissie' ${ }^{1}$ (iD \\ ${ }^{1}$ National Research Moscow State University of Civil Engineering (NRU MSUCE), Moscow, Russia \\ ${ }^{2}$ Research Institute of Building Physics Russian Academy of Architecture and Construction Sciences \\ (RAACS, transliterating the Russian acronym, RIBPh RAACN), Moscow, Russia \\ ${ }^{3}$ National Research University Higher School of Economics, (NRU HShE), Moscow, Russia \\ * Corresponding author: e-mail: mla-gasis@mail.ru
}

\begin{abstract}
Introduction. The use of gypsum in construction systems exposed to atmospheric influences involves the introduction of modifying additives of various types: polymer compositions, mineral fine and nanodisperse components, which can also be products of other industries. Methods and materials. To increase the weather resistance of gypsum stone, its strength characteristics and water resistance, the research considered a complex method of modifying gypsum binder by introducing aqueous solutions of polycondensation resins that harden in the material and nanocomponents. The experiment to assess the effect of the composition of complexly modified gypsum on its properties was carried out on the basis of the matrix of a complete quadratic three-factor experiment. Results. The strength of a complex modified gypsum stone during compression and bending increases by $30 \%$ and $25 \%$, respectively, during 80 days of storage in the air. The compressive strength is $60 \mathrm{MPa}$, and the bending strength is $12 \mathrm{MPa}$. The samples can withstand 150 cycles of alternating freezing and thawing. Discussion. The introduction of polymer additives into the composition of the gypsum mixture leads to the fact that the gypsum during hydration creates a framework of crystalline aggregates of dehydrate, and the resin, when cured, forms a continuous polymer matrix. The polymer gypsum has the property of increasing the strength over time due to the ongoing polymerization of the resin. Conclusion. A weather-resistant gypsum-containing material was obtained. The use of man-made waste makes it possible to solve the problem of their disposal, which determines the reduction of the negative load on the environment. The methodology for assessing the weather resistance of gypsum stone, and, first, frost resistance, was tested.
\end{abstract}

KEY WORDS: gypsum stone, water-soluble polymers, techno-genic additives, nanotubes, water resistance, strength.

FOR CITATION: Zhukov A.D., Bessonov I.V., Bobrova E.Yu., Gorbunova E.A., Demissie B.A. Materials based on modified gypsum for facade systems. Nanotechnologies in Construction. 2021; 13(3): 144-149. Available from: doi: 10.15828/2075-8545-2021-13-3-144-149.

\section{INTRODUCTION}

$\mathrm{T}$ he use of gypsum-containing materials in facade systems is limited, first of all, by the low water resistance of gypsum stone, while gypsum materials and products are widely used in finishing works inside buildings. For this purpose, plasterboard or gypsum-fiber sheets, stucco decoration products, self-leveling floors, a variety of dry plaster, putty and adhesive gypsum mixtures, wall stones are used.

In connection with the trend of expanding the scope of application of products based on gypsum binders, not only for interior decoration, but also for the facades of buildings under construction and under reconstruction, several areas of research have been formed.
First, it is the study of the possibility of using various mineral additives, as well as the use of man-made gypsum-containing products that form an increased resistance of gypsum stone to atmospheric influences. Many researchers propose to achieve an increase in the water resistance of gypsum stone by modifying the binder component with pozzolans, in particular, gypsum-cementpuzzolane (GCP) and gypsum-slag-cement-puzzolane (GSCP) were developed; technologies of composite (DTC) and water-resistant gypsum binder of low water demand (WRGB) were developed [1-3]. Secondly, it is the development of scientific foundations for the directed formation of the structure and properties of anhydrite, gypsum compositions and stone under the action of

(c) Zhukov A.D., Bessonov I.V., Bobrova E.Yu., Gorbunova E.A., Demissie B.A., 2021 
micro - ultra - and nanodisperse systems. Third, these are studies aimed at surface or bulk hydrophobization of gypsum stone [4-6].

The range of technogenic gypsum-containing materials is quite wide, but the largest amount of research was conducted on phosphogypsum and its modifications. Energysaving technologies for processing phosphodihydrate and phosphopolohydrate have been developed, as well as methods for its application in wall structures, stucco decorative compositions made of gypsum and finishing compositions of artificial marbles based on organic dyes [7, 8].

The possibility of using various mineral technogenic additives on the properties of gypsum binders [9, 10], the possibility of using hollow glass microspheres to obtain lightweight gypsum material for restoration work [11], as well as the possibility of modifying anhydrite and gypsum compositions with ultra-fine-grained technogenic additives [12] were also studied.

Carbon nanotubes and fullerenes are promising both in terms of their use as crystallization centers and as objects that change the direction and speed of physicochemical processes in hardening materials [13, 14]. The nanocarbon structures used to modify the gypsum binder can be waste from other industries, in particular, ultrafine dust from blast furnaces can be used $[15,16]$.

Nanotubes introduced into the mortar mixture reinforce the gypsum stone. From the point of view of common sense, such a percentage of reinforcement seems clearly insufficient to significantly affect the strength characteristics. Nevertheless, a persistent effect is present, but it occurs not due to direct reinforcement, which is really insignificant, but due to the directed regulation of crystallization processes. Nanotubes behave in the gypsum solution as "embryos" of crystals, growing, the crystals intertwine, partially grow into each other and form a spatial network that permeates and binds the entire gypsum stone into a single whole $[17,18]$.

It is possible to increase the water and weather resistance of gypsum stone due to its volumetric or surface hydrophobization. Surface treatment with hydrophobizers tends to lose its effectiveness over time, and, for longer use of products, it must be repeated periodically. The frequency of treatment with hydrophobizers depends on the operating conditions of the products.
Volumetric hydrophobization is carried out by the introduction of various polymers in the form of aqueous solutions or emulsions, including aminoaldehyde resins with non-linear monomers (melamine, resorcinol, benzoguanamine). Resins of this type belong to polycondensation, i.e., during curing, low-molecularweight products, in particular water, are released. For the chemical binding of the released water, a structuring additive based on polyisocyanates was introduced into the composition [19-21].

Taking into account the existing experience, a complex method of modifying a gypsum binder by introducing aqueous solutions of polycondensation resins that harden in the material and nanocomponents is considered in the research. It should be noted that the use of products based on modified gypsum binder in facade systems is directly related to the development of methods for assessing the weather resistance of gypsum stone, and, first of all, frost resistance.

\section{METHODS AND MATERIALS}

In the experiment, we used gypsum binder grades G 7...G 10, melamine formaldehyde resin, carbon clusters (nanotubes) Carbon clusters are hollow tubes made of one or more layers of carbon atoms. They have a diameter of one to several nanometers and a length of several diameters to several microns, they are essentially hollow fibers.

The influence of the composition of the complex modified gypsum on its properties was evaluated on the basis of the matrix of a complete quadratic threefactor experiment. The obtained regression equations were checked against all statistical hypotheses and the adequacy of the models was checked according to the Fisher criterion.

In the experiment, the strength of the gypsum binder $\left(\mathrm{X}_{1}\right)$, the consumption of melamine formaldehyde resin $\left(\mathrm{X}_{2}\right)$, and the consumption of the nanoadditive $\left(\mathrm{X}_{3}\right)$ were taken as variable factors. The response function is the strength of the gypsum stone after 7 days of hardening of the samples $\left(\mathrm{Y}_{1}\right)$, and the optimization parameter is the softening coefficient of the gypsum stone samples according to the results of climatic tests $\left(\mathrm{Y}_{2}\right)$. The experimental conditions are shown in Table 1.

\section{Table 1}

\section{Intervals of variation of factors}

\begin{tabular}{|l|c|c|c|c|c|}
\hline \multirow{2}{*}{$\begin{array}{c}\text { Name of the factor } \\
\end{array}$} & Symbol $\mathbf{X}_{\mathbf{i}}$ & $\begin{array}{c}\text { Average value } \\
\text { of the factor, } \overline{\mathbf{X}}_{\mathbf{i}}\end{array}$ & $\begin{array}{c}\text { Variation } \\
\text { interval, } \mathbf{\Delta} \mathbf{X}_{\mathbf{i}}\end{array}$ & \multicolumn{2}{|c|}{ Factor values at levels } \\
\cline { 4 - 6 } & & 6 & 1 & $\mathbf{- 1}$ & 5 \\
\hline Gypsum strength, $\mathrm{MPa}$ & $\mathrm{X}_{1}$ & 13 & 3 & 10 & 16 \\
\hline Resin expenditure, $\%$ & $\mathrm{X}_{2}$ & 0.04 & 0.01 & 0.03 & 0.05 \\
\hline Nanoadditive consumption, $\%$ & $\mathrm{X}_{3}$ & & 1 & 7 \\
\hline
\end{tabular}


Along with conducting frost resistance tests on cube samples, the effects of cyclical climatic influences on the products themselves were studied. The test cycle consists in the fact that one of the sides of the fragment was directed to the cold zone of the chamber with a temperature of $-18^{\circ} \mathrm{C}$, and the second - to the warm zone with a temperature of $+18^{\circ} \mathrm{C}$. For 2 hours, the side facing the warm zone can be exposed to ultraviolet radiation, and for the next 2 hours, it is irrigated with water in such a way that the moistened surface of the sample is frozen during rotation. The rotation of the clip, and, consequently, the test fragments, is carried out every 4 hours.

\section{RESULTS}

Mathematical processing of the experimental results allowed us to obtain regression equations for the compressive strength of the gypsum polymer samples $\left(\mathrm{Y}_{1}\right)$ and its softening coefficient $\left(\mathrm{Y}_{2}\right)$. The significance of the coefficient was checked by confidence intervals, respectively, the confidence interval for strength was $\Delta b_{1}=0.01 \mathrm{MPa}$, and the softening coefficient was $\Delta b_{2}=0.04$.

The following mathematical models (polynomials) are obtained:

- For compressive strength:

$$
\mathrm{Y}_{1}=64+14 \mathrm{X}_{1}+9 \mathrm{X}_{2}+8 \mathrm{X}_{3}+4 \mathrm{X}_{1} \mathrm{X}_{3}+2 \mathrm{X}_{2} \mathrm{X}_{3}
$$

- For the softening factor:

$$
\mathrm{Y}_{2}=0.84+0.03 \mathrm{X}_{1}+0.09 \mathrm{X}_{2}+0.07 \mathrm{X}_{3}+0.04 \mathrm{X}_{1} \mathrm{X}_{3}-0.05 \mathrm{X}_{2}^{2}
$$

The obtained models were checked for adequacy according to the Fisher criterion. The calculated values of the Fischer criteria are equal for the compressive strength model $F_{1}=15.2$ and for the softening coefficient model $\mathrm{F}_{2}=15.7$. The tabular values of the criteria, respectively, are 19.2 and 19.3. The calculated values of the F-criterion do not exceed the tabular one, and with the corresponding confidence probability (98\%), the model can be considered adequate. This fact will be taken into account in the analytical optimization of mathematical models.

\section{DISCUSSION}

Analysis of the coefficients of the equation $Y_{1}=f_{1}\left(X_{1}\right.$, $\mathrm{X}_{2}, \mathrm{X}_{3}$ ) shows that the strength of the composite modified binder increases with an increase in the strength of the stone without additives (gypsum grade), the consumption of resin and nanocomponent at the intervals taken in the experiment (positive coefficients at $X_{1}, X_{2}, X_{3}$ ).

The analysis of the coefficients of the equation $Y_{2}=$ $f_{2}\left(\mathrm{X}_{1}, \mathrm{X}_{2}, \mathrm{X}_{3}\right)$ shows that the greatest influence on the softening coefficient is exerted by an increase in the consumption of resin and nanoderms. At the same time, at high resin consumption, the strength growth slows down (coefficient at $\mathrm{X}_{2}^{2}$ ), which can be explained by the limited access to the reaction surfaces.

Significant effects of pair interactions (in terms of strength and softening coefficient at $X_{1} X_{3}$ and in terms of strength at $\mathrm{X}_{2} \mathrm{X}_{3}$ ) have been established, which allows us to assume the presence of synergistic effects of the influence of resin consumption and nanoadditive on the strength and softening coefficient of gypsum stone during its complex modification. The function $\mathrm{Y}_{2}=f_{2}\left(\mathrm{X}_{1}, \mathrm{X}_{2}, \mathrm{X}_{3}\right)$ (which is essentially a function of several variables) for one of these variables, the resin consumption $\left(\mathrm{X}_{2}\right)$, has a local ex-tremum. Therefore, we can use the mathematical apparatus of analytical local optimization..

Analytical optimization is based on the fact that the functions for strength and density $Y_{1}=f_{1}\left(X_{1}, X_{2}, X_{3}\right)$ and $\mathrm{Y}_{2}=f_{2}\left(\mathrm{X}_{1}, \mathrm{X}_{2}, \mathrm{X}_{3}\right)$ are mathematical and mathematical analysis methods can be applied to them, provided that the adequacy condition is not violated. In this case, the following scheme is adopted:

- the algebraic polynomial $\mathrm{Y}_{2}=f_{1}\left(\mathrm{X}_{1}, \mathrm{X}_{2}, \mathrm{X}_{3}\right)$ is differentiated by $\mathrm{X}_{2}$ and equated to zero by determining the extreme of the function $\mathrm{Y}_{2}$ by $\mathrm{X}_{2}$;

- solve the functions $\mathrm{Y}_{1}=f_{1}\left(\mathrm{X}_{1}, \mathrm{X}_{2}, \mathrm{X}_{3}\right)$ and $\mathrm{Y}_{2}=f_{2}\left(\mathrm{X}_{1}\right.$, $\mathrm{X}_{2}, \mathrm{X}_{3}$ ) for $\mathrm{X}_{2}=\mathrm{opt}$ and perform local optimization.

1) Analytical optimization involves the following sequence of actions:

We determine the value of the local extreme of the function $Y_{1}$ by $X_{2}$ :

$$
\partial \mathrm{Y}_{2} / \partial \mathrm{X}_{2}=0.9-1.0 \mathrm{X}_{2}=0 \rightarrow \mathrm{X}_{2}=0.09
$$

2) We calculate the value of the natural value of the resin consumption (corresponding to the possible obtaining of the maximum compressive strength of the polyhypse) using the factor decoding formula:

$$
\widetilde{\mathrm{X}}_{2}=\overline{\mathrm{X}}_{2}+\Delta \mathrm{X}_{2} \cdot 0.9=13+3 \cdot 0.9=15.7 \%
$$

3) We calculate mathematical models (polynomials) for the optimized value of the factor $\mathrm{X}_{2}=0.9$ :

- For compressive strength:

$$
Y_{1}=73+14 X_{1}+8 X_{3}+4 X_{1} X_{3}
$$

- For the softening factor:

$$
\mathrm{Y}_{2}=0.89+0.03 \mathrm{X}_{1}+0.07 \mathrm{X}_{3}+0.04 \mathrm{X}_{1} \mathrm{X}_{3}
$$

The introduction of polymer additives (polycondensation resins) into the mixture leads to the fact that gypsum during hydration creates a framework of crystalline aggregates of bi-hydrate, and the resin, when cured, forms a continuous polymer matrix. The pores in the plaster body are filled with a vitreous substance. The perme- 

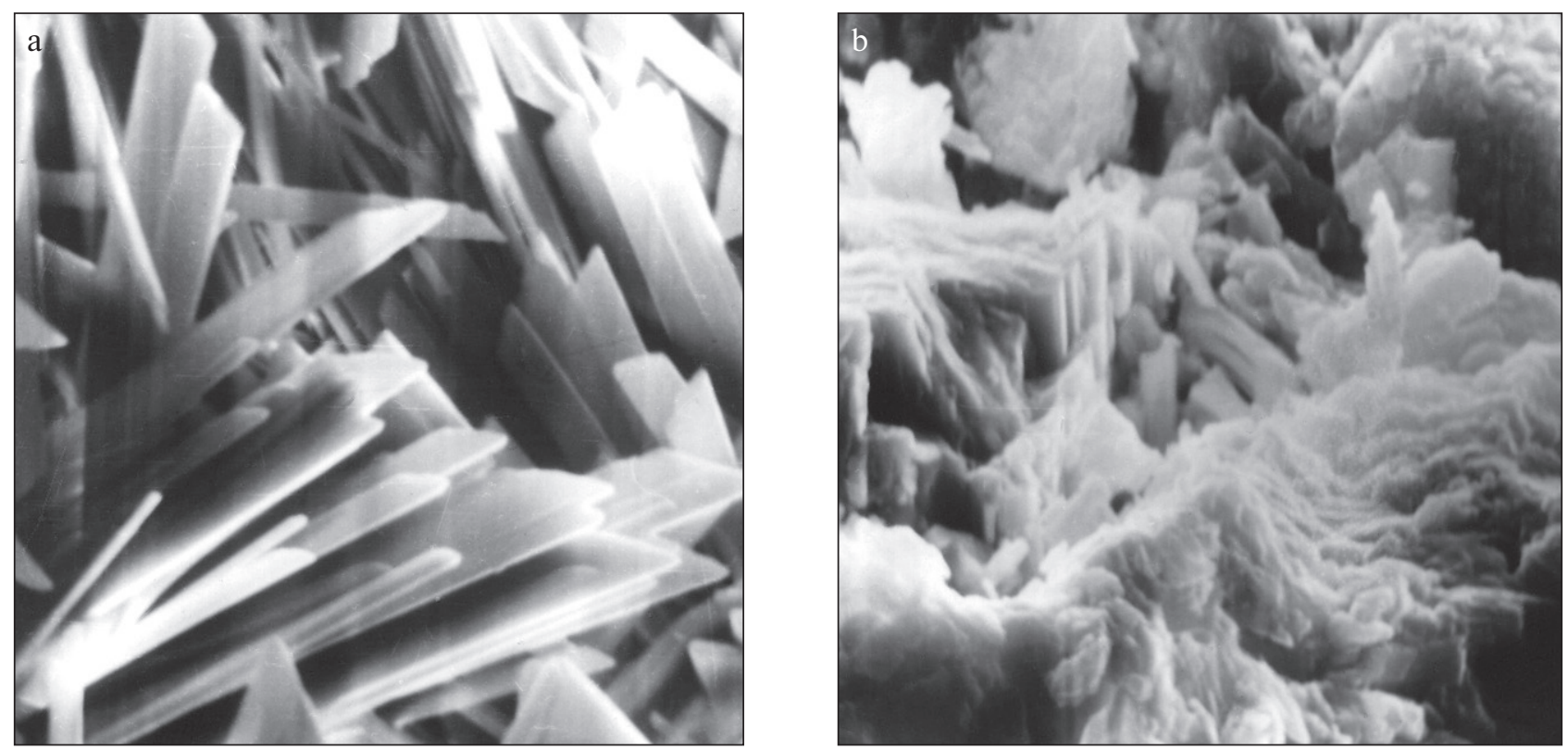

Fig. 1. Structure of gypsum stone: $a$ - without additives; $b$ - structure of modified gypsum stone

ability of the material to liquid moisture is significantly reduced. The resulting protective screen of a polymer film around the gypsum crystals prevents water from reaching the highly soluble calcium sulfate.

The photos taken at a 2400 -fold magnification on a raster electron microscope (Fig. 1) show that the material structure is a polymer grid, which is a continuous phase located in a three-dimensional skeleton of crystallized gypsum. Accretions of hydrate neoplasms, lamellar in structure, permeate the polymer blocks. In the pores there is a crystallization of small gypsum crystals of prismatic and needle shape.

When the age of the samples increases, there are no significant changes in the characteristics of the composite. The increase in strength over time can be explained by the continued polymerization of the resin. The degree of polymerization of the resin in the presence of a hardener under natural conditions is almost the same as during heat treatment.

The introduction of carbon nanosystems changes the structure of gypsum crystals, as well as the phase composition, in the direction of increasing the content of calcium sulfate dehydrate. The morphology of the crystals is transformed from lamellar to diamond-shaped with a denser packing of the crystals, while there is a decrease in the defects of the crystals themselves. The use of modifying additives in the form of carbon nanosystems in the preparation of a fluorohydrite composition makes it possible to increase the physical and mechanical properties of products based on it, to improve the thermophysical characteristics of the composition by reducing its thermal conductivity. It is noted that the introduction of carbon nanosystems into porous fluorohydrite compositions re- sults in the activation of anhydrite hydration, increases the strength of the compositions, and improves the uniformity and stability of the pores [9].

The anisotropy and high mechanical and thermodynamic stability of the shape of most fulleroids determine the stability of their properties. The very large sizes compared to ordinary organic molecules determine their ability to transform into abnormally large dipoles in external fields. The induced dipole moment, for example, of nanotubes, can reach several thousand Debye. It is logical to consider fullerides as a potential tool for modifying interphase boundaries in a wide variety of condensed media, and with small amounts of nanomodifiers, which is confirmed in practice.

The strength of kop - modified gypsum stone under compression and bending during 80 days of storage in the air increases by $30 \%$ and $25 \%$, respectively. The compressive strength is $60 \mathrm{MPa}$, and the bending strength is $12 \mathrm{MPa}$. The samples can withstand 150 cycles of alternating freezing and thawing. The vapor permeability of the gypsum polymer is $0.092 \mathrm{mg} /(\mathrm{m} \cdot \mathrm{h} \cdot \mathrm{Pa})$.

\section{CONCLUSIONS}

The expansion of the areas of application of gypsumcontaining materials is due, on the one hand, to the requirements of the construction products market, and, on the other hand, to the capabilities of gypsum itself, which are currently still not fully implemented in modern technologies.

The existing experience shows the possibility of using gypsum-containing systems on the facades of buildings, which makes it necessary to increase the frost resistance 
and moisture resistance of gypsum canvas to the level required for materials used in contact with the environment. A significant role for the realization of such properties is performed by a complex modification of the gypsum binder as the basis of the material. The modifying effect can be realized through the use of water-soluble polymers that harden in the body of gypsum stone, mineral additives of the micro-and nanoscale, nanosystems of the fuleroid type. Of particular interest is the possibility of using man-made waste to modify gypsum-containing systems.

\section{REFERENCES}

1. Buryanov A.F. Gypsum, its research and application from P.P. Budnikov to the present day. Construction materials. 2005; 9: 46-48.

2. Volzhensky A.V., Ferronskaya A.V. Gypsum binders and products. Moscow: Stroyizdat; 1974.

3. Volzhensky A.V., Ferronskaya A.V. Gypsum binders and products. Moscow: Stroyizdat; 1974. - 328 p.

4. Bessonov I.V. Gypsum of increased water resistance / 3 scientific and practical conference "Problems of construction thermo physics and energy saving in buildings". Collection of Papers. Moscow: NIISF; 1998.

5. Panchenko A.I., Buryanov A.F., Kozlov N.V., Solovyov V.G., Pashkevich S.A. Complex assessment of the effectiveness of the use of gypsum binder with increased water resistance. Construction materials. 2014; 12 : $72-74$.

6. Meshheryakov Yu.G., Fedorov S.V. Die baustoffproduction mittels der dielectrischen. Int.Congress Euro ECO. Hannover; 2010.

7. Meshheryakov Yu.G., Tairov T.N., Fedorov S.V. Processing of complex production of anhydzite and gypsum binder into. Congress trade fair Euro ECO. Hannover; 2011.

8. Meshcheryakov Yu.G., Fedorov S.V. Energy-saving technologies for processing phosphogypsum and phosphopoluhydrate. Construction materials. 2005; 12: 56-57.

9. Bozhenov P.I., Meshheryakov Yu.G. Influence of the admixtures and the technical characteristics son Gipsbinderu. 6 Int. Building materials and Sieikattagung Weimaz. 1976.

10. Sychugov S., Tokarev Y., Plekhanova T., Kazantseva A., Gaynetdinova D. Binders Based on Natural Anhydrite and Modified by Finely-Dispersed Galvanic and Petrochemical Waste. Procedia Engineering Modern Building Materials, Structures and Techniques. 2013; 57: 1022-1028.

11. Khaev T.E., Tkach E.V., Oreshkin D.V. Modified lightweight gypsum material with hollow glass microspheres for restoration work. Construction materials. 2017; 10: 45-51.

12. Yakovlev G., Polyanskikh I., Fedorova G., Gordina A., Buryanov A. Anhydrite and gypsum compositions modified with ultrafine man-made admixtures. Procedia Engineering " $7^{\text {th }}$ Scientific Technical Conference Material Problems in Civil Engineering”. 2018; Vol. 108: 13-21.

13. Pisarenko Zh.V., Ivanov L.A., Wang Q. Nanotechnology in Construction: State of the Art and Future Trends. Nanotechnologies in Construction. 2020; 12(4):223-231. Available from: doi: 10.15828/2075-8545-2020-12-4-223-231.

14. Sanchez F., Sobolev K. Nanotechnology in concrete - A review. Construction and Building Materials. 2010; 24 : 2060-2071. Available from: doi: 10.1016/j.conbuildmat.2010.03.014

15. Yakovlev G., Khozin V., Polyanskikh I., Keriene J., Gordina A., Petrova T. Utilization of blast furnace flue dust while modifying gypsum binders with carbon nanostructures. In: The $9^{\text {th }}$ International Conference "ENVIRONMENTAL ENGINEERING” 22-23 May 2014, Vilnius, Lithuania. 2014. p.1-5.

16. Gordina A., Tokarev Y., Yakovlev G., Keriene J., Sychugov S., Sayed Mohamed Ali El. Evaluation of the Influence of Ultradisperse Dust and Carbon Nanostructures on the Structure and Properties of Gypsum Binders. Procedia Engineering Modern Building Materials, Structures and Techniques.2013; 57: 334-342.

17. Yakovlev G.I., Pervushin G.N., Krutikov V.A., Makarova I.S., Kerene Ya., Fischer Kh.-b., Buryanov A.F. Aerated concrete based on fluoroanhydrite, modified by carbon nanostructures. Construction materials. $2008 ; 3:$ 70-72.

18. Izryadnova O., Yakovlev G., Nurieva L., Sychugov S., Pervuchin G. Role of polyfunctional admixture based on silica fume and carbon nanotubes in forming the structure of gypsum cement composition. Procedia Engineering “7th Scientific Technical Conference Material Problems in Civil Engineering”. 2015; 108: 380-386.

19. Batrakov V.G. Modified concrete. Theory and practice. Moscow: Stroyizdat; 2008.

20. Pustovgar A.P., Buryanov A.F., Vasilik P.G. Features of the use of hyperplasticizers in dry building mixes. Construction materials. 2010; 12: 61-64.

21. Bessonov I.V. "Stolitsa" - weather-resistant gypsum facing of buildings. Building materials. 1999; 9: $12-14$. 
22. Zhukov A., Shokodko E., Bobrova E., Bessonov I., Dosanova G., Ushakov N. Interior Acoustic Materials and Systems. EMMFT-2018. Advances in Intelligent Systems and Computing. 983: 740-747. Available from: doi: 10.1007/978-3-030-19868-8 72.

23. Zhukov A., Shokodko E. Mathematical Methods for Optimizing the Technologies of Building Materials. VIII International Scientific Siberian Transport Forum. TransSiberia 2019. Advances in Intelligent Systems and Computing. 2020; 1116: 413-421. Springer, Cham. Available from: doi: 10.1007/978-3-030-37919-3 40.

24. Bessonov I., Zhukov A., Shokodko E., Chernov A. Optimization of the technology for the production of foam glass aggregate. TPACEE 2019, E3S Web of Conferences. 2020; 164: 14016. Published online: 05 May 2020. Available from: doi: $10.1051 / \mathrm{e} 3 \mathrm{sconf} / 202016414016$.

\section{INFORMATION ABOUT THE AUTHORS}

Alexey D. Zhukov, Associate Professor, Cand. Sci. (Eng.), Associate Professor of the Department of Building Materials and Materials Science of the National Research Moscow State University of Civil Engineering (NRU MSUCE), Leading Researcher of the Research Institute of Building Physics of the Russian Academy of Architecture and Building Sciences (RIBPh RAASN), Deputy Director of the REC of Complex Modernization of Housing and Utilities Infrastructure of the GASIS Institute of the National Research University Higher School of Economics (NRU HSE), Corresponding Member of the Russian Academy of Engineering (RIA), Moscow, Russia, ORCID: https://orcid.org/0000-0003-0593-3259, e-mail: lj211@yandex.ru

Igor V. Bessonov, Cand. Sci. (Eng.), Chief Researcher of the Research Institute (RIBPh RAACS), Advisor to the Russian Academy of Architecture and Construction Sciences (RAACS), Moscow, Russia, ORCID: https://orcid.org/0000-0002-9234-4075, e-mail: bessonoviv@mail.ru

Ekaterina Yu. Bobrova, Cand. Sci. (Econ.), Sciences, Advisor to the Director of the Institute of Construction and Housing and Communal Services of the State Academy of Investment Specialists of the National Research University Higher School of Economics (HSE), Moscow, Russia, ORCID: https://orcid.org/0000-0001-6541-4552, e-mail: mla-gasis@mail.ru

Elina A. Gorbunova, Undergraduate student of the National Research Moscow State University of Civil Engineering (NRU MSUCE), Engineer of the Research Institute of Civil Engineering Physics of the Russian Academy of Architecture and Civil Engineering Sciences (RIBPh RAACS), Moscow, Russia, ORCID: https://orcid.org/0000-0002-7241-4136, e-mail: eg15082000@mail.ru

Bekele Arega Demissie, Master of Science (MSc.) in Construction, post-graduate student (PhD. Candidate) at the Department of Building materials and materials science, in Moscow state University of Civil Engineering (National Research University), Moscow, Russia ORCID: https://orcid.org/0000-0003-1689-7003, email:aregabekalu@gmail.com

\section{Authors declare the absence of any competing interests.}

Received: 08.04.2021.

Revised: 27.04.2021.

Accepted: 13.05.2021. 